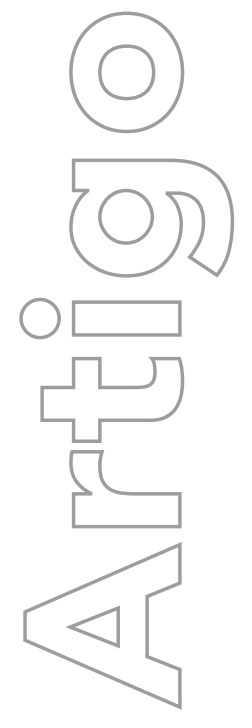

revista

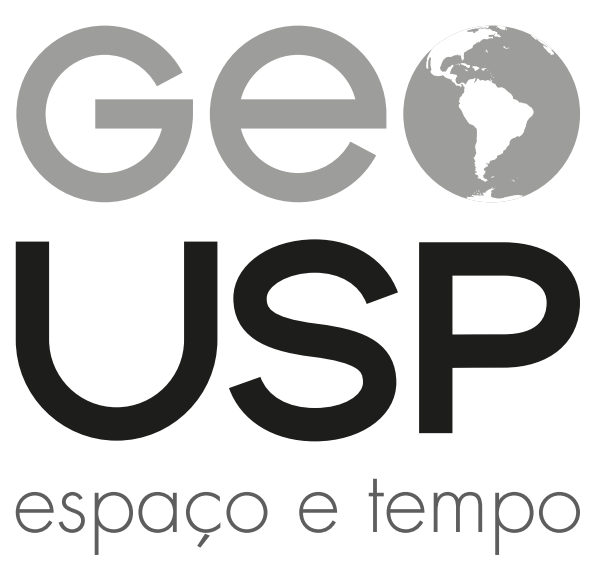

Volume $25 \cdot n^{\circ} 1$ (2021)

ISSN 2179-0892

\section{Uma proposta metodológica para mapear a dissecação do relevo e aplicá-la no Parque Nacional da Serra da Canastra-MG}

José Roberto Mantovani ${ }^{\mathrm{a}}$

a Universidade Federal de Goiás. Instituto de Estudos Socioambientais. Goiânia. Goiás. Brasil jr.mantovani.geo@gmail.com (1) 0000-0002-7051-5304

Guilherme Taitson Bueno ${ }^{b}$ bUniversidade Federal de Goiás. Instituto de Estudos Socioambientais. Goiânia. Goiás. Brasil gtaitsonbueno@gmail.com (1) 0000-0003-4259-7354 e-170745

Como citar este artigo:

MANTOVANI, J. R.; BUENO, G. T. Uma proposta metodológica para mapear a dissecação do relevo e aplicá-la no Parque Nacional da Serra da Canastra-MG. Geousp, v. 25, n. 1, p.1-19 e-170745, abr. 2021. ISSN 2179-0892.

Disponível em: https://www.revistas.usp.br/geousp/article/ view/170745.https://doi.org/10.11606/issn.2179-0892. geousp.2021.170745.

\section{(c)}

Este artigo está licenciado sob a Creative Commons Attribution 4.0 Licence 


\section{Uma proposta metodológica para mapear a dissecação do relevo e aplicá-la no Parque Nacional da Serra da Canastra-MG ${ }^{1}$}

\section{Resumo}

Este trabalho propõe um mapa da dissecação do relevo por meio da técnica de geovisualização bivariada. Esse mapa permite verificar a influência de cada variável, entalhamento do vale e dimensão interfluvial, de forma separada ou combinada. O Parque Nacional da Serra da Canastra, no sudoeste de Minas Gerais, foi escolhido para aplicação do método devido a suas características geomorfológicas e a sua amplitude altimétrica. $\bigcirc$ resultado do mapa bivariado apresentado mostrou equivalência com outras propostas aplicadas existentes na literatura brasileira, com boa precisão e correlação espacial, principalmente onde a dissecação é "muito forte". A vantagem dessa metodologia é a universalidade, pois sua aplicação independe da base de dados utilizada e prescinde da interferência do tomador de decisões, a partir do modelo digital de elevação (MDE) de qualquer região geográfica.

Palavras-chave: Dissecação do relevo. Geovisualização bivariada. Parque Nacional Serra da Canastra.

\section{A methodological proposal for mapping the dissection of the relief in the Canastra National Park-MG}

\section{Abstract \\ This work proposes a map of the relief dissection using the bivariate geovisualization technique. This map makes it possible to verify the influence of each variable; notching of the valley and interfluvial dimension, separately or combined. The Serra da Canastra}

1 Os autores agradecem a Coordenação do Pessoal de Nível Superior (Capes) pela bolsa de doutorado sob o Processo n. 88882.385705/2019-01. 
National Park, southwest of Minas Gerais, was chosen to apply the method due to its geomorphologic characteristics and altimetry amplitude. The results presented by bivariate map, showed equivalence with the other proposals existing in the Brazilian literature, with good precision and spatial correlation, mainly where the dissection is "very strong". The methodology has the advantage of universality, since its application does not depend on the database used, without the need for interference by decision makers, based on the digital elevation model (DEM) of any geographic region.

Keywords: Relief dissection. Bivariate Geoview. Serra da Canastra National Park.

\section{Una propuesta metodológica para mapear la disección del relieve y aplicarla en el Parque Nacional Serra da Canastra-MG}

\section{Resumen}

Se propone un mapa de disección de relieve por medio de la técnica de geovisualización bivariada. El mapa posibilita verificar la influencia de las variables; inclinación del valle y dimensión interfluvial, de forma separada o combinada. El Parque Nacional Serra da Canastra, suroeste de Minas Gerais, fue elegido para la aplicación del método debido a sus características geomorfológicas y amplitud altimétrica. El resultado del mapa bivariado presentado mostró equivalencia con las otras propuestas aplicadas existentes en la literatura brasileña, con buena precisión y correlación espacial, especialmente donde la disección es "muy fuerte". La metodología tiene como ventaja la universalidad, ya que su aplicación no depende de la base de datos utilizada, sin necesidad de interferencia del usuario, a partir del modelo digital de elevación (MDE) de cualquier región geográfica.

Palabras clave: Disección en relieve. Geovisualización bivariada. Parque Nacional Serra da Canastra.

\section{Introdução}

Óndice de dissecação do relevo consiste num parâmetro morfométrico fundamental para se compreender a gênese das paisagens e ajudar no planejamento e na gestão ambientais (Ross, 1994). Pode ser empregado para diversos fins: entender a organização e a evolução das paisagens, avaliar fragilidade ambiental e detectar áreas de risco, entre outros. Atualmente, é cada vez 
maior a necessidade de que a administração pública tenha documentos atualizados que orientem o planejamento da ocupação centrado no princípio do desenvolvimento sustentável e/ou equilibrado, de modo a indicar diferentes níveis de restrição ao uso e ocupação. Assim, este trabalho apresenta uma proposta de mapeamento do índice de dissecação aplicada ao Parque Nacional da Serra da Canastra (PNSC), parâmetro que ajuda a compreender a dinâmica ambiental e as práticas de preservação em diferentes escalas.

Queiroz Neto (1978), faz um balanço dos resultados obtidos em estudos e pesquisas científicas que abordam diferentes aspectos do ambiente e seu uso: uso racional do solo, potencial em recursos naturais, consequências dos usos nas águas e no ar, busca de soluções alternativas de usos de recursos naturais renováveis e não renováveis. $\bigcirc$ autor constata "a ausência de pesquisas e estudos, mesmo de orientação, no sentido de se obter uma avaliação global dos elementos do meio ambiente, inclusive das duas dinâmicas, tanto os naturais como as degradações, poluições e sistemas de controle" (QUEIROZ NETO, 1978, p. 5). Nesse sentido, o índice de dissecação é fácil de obter e muito contribui na avaliação global dos elementos do meio ambiente.

Nos últimos anos, o avanço tecnológico, principalmente o desenvolvimento de geotecnologias, vem sendo cada vez mais utilizado, alterando o estado da arte nos conceitos e no desenvolvimento de metodologias de pesquisa geográfica. Destacam-se o Sistema de Informação Geográfica (SIG), o geoprocessamento e os produtos do Sensoriamento Remoto, que permitem integrar técnicas aos conceitos teóricos, além de possibilitarem o armazenamento de diversos tipos de dados geográficos. Constituem-se em mecanismos importantes de análise, estudo e planejamento do espaço. Por meio de imagens orbitais de satélite, é possível analisar estrutura e a dinâmica da paisagem em diferentes escalas espaciais e temporais, variando conforme a configuração do sensor (Albuquerque et al., 2014).

Com eminente potencial ecoturístico, o PNSC está na porção sudoeste do estado de Minas Gerais, divisa com São Paulo, tratando-se de uma unidade de conservação de proteção integral. Com toda essa importância do parque, ainda não existem estudos aprofundados sobre a dinâmica e a degradação do ambiente, e o mapeamento de índices morfométricos, como o de dissecação pode subsidiar estudos nessa direção. Além de suas características geomorfológicas, como grande amplitude altimétrica e heterogeneidade de formas de relevo, esses aspectos explicam sua escolha como área experimental deste estudo.

As propostas metodológicas para mapeamento da dissecação do relevo disponíveis na literatura brasileira, apoiadas teoricamente na matriz de dissecação proposta por Ross (1994), são dependentes de limiares fundamentalmente preestabelecidos. A classificação é feita conforme a proposição destes limiares, que dependem fundamentalmente da base de dados existentes, em específico, das características topográficas do terreno. Muitas vezes, em razão das características físicas/geográficas da área de estudos, essas metodologias podem ser inaplicáveis ou inviáveis, em razão dos valores de limiares preestabelecidos para sua aplicação.

$\bigcirc$ principal objetivo deste trabalho é apresentar uma nova proposta de mapeamento da dissecação de relevo, baseada numa técnica já existente geovisualização bivariada de Stevans, 2015, mas não aplicada ainda para esse fim. O produto final permite verificar a influência de cada variável, entalhamento do vale e dimensão interfluvial, de forma separada ou combinada. 
Para avaliar os resultados obtidos pela metodologia adotada, foram aplicadas na mesma área as propostas de Ross (1994) e de Guimarães et al. (2017) e realizado um trabalho de campo num ponto específico da área de estudo.

\section{Material e métodos}

\section{Área de estudo}

$\bigcirc$ Parque Nacional da Serra da Canastra (PNSC) situa-se no sudoeste de Minas Gerais, com aproximadamente 200 mil hectares. No Parque, encontra-se o divisor de águas das bacias dos rios São Francisco e Paraná, nesse caso, contribuindo, ao sul, com o Rio Grande e, ao norte, com o Paranaiba. Abrange quatro municípios mineiros: São João Batista do Glória, Delfinópolis, São Roque de Minas e Vargem Bonita (Figura 1).

\section{Figura 1 - Localização da área de estudo: (a) mapa hipsométrico, b) mapa de declividade, c) situação geográfica}

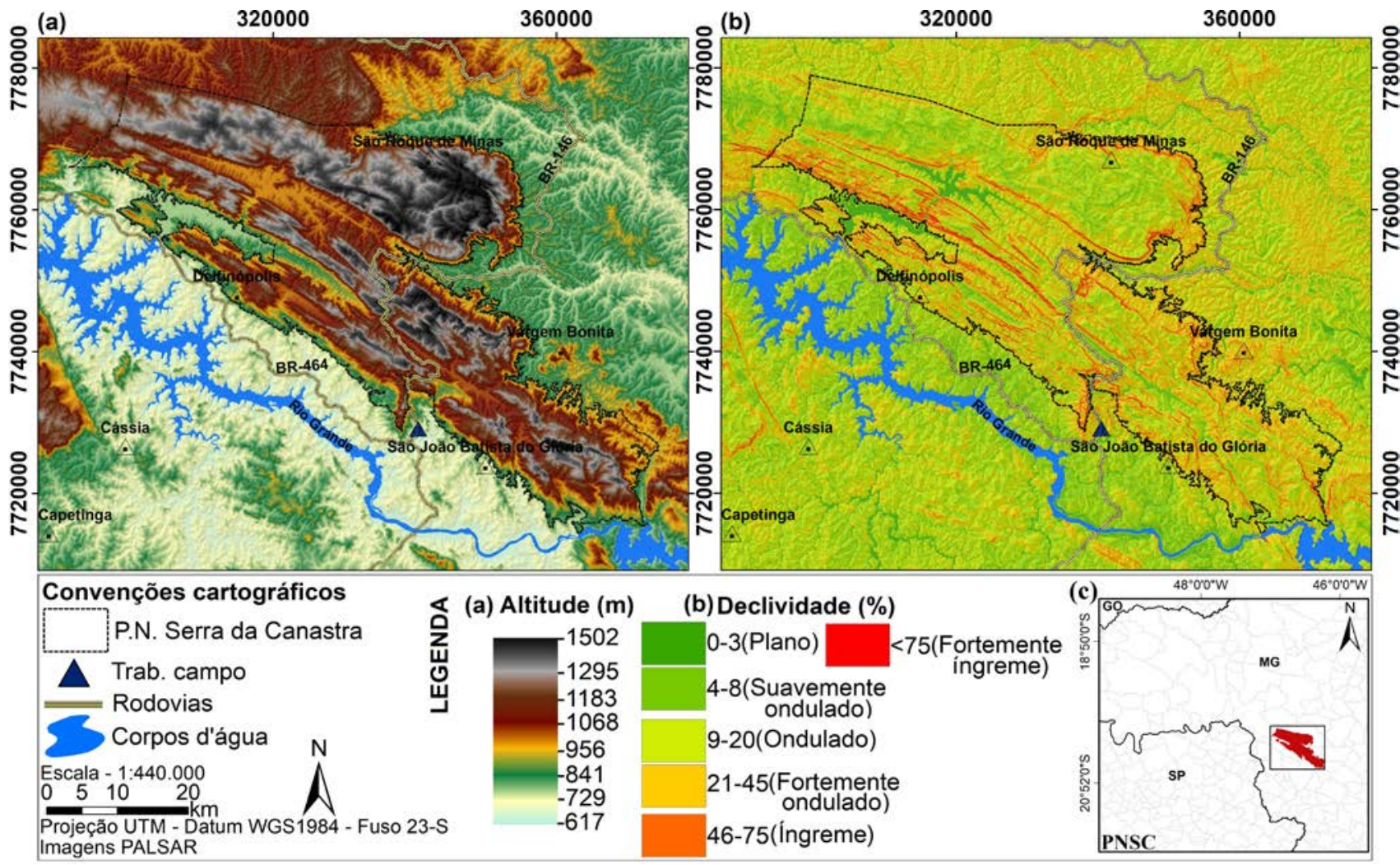

fonte: Elaborada pelos autores, 2020.

A área do PNSC e seu entorno situam-se no domínio fitogeográfico do Cerrado. A área pertence às zonas da savana gramíneo-lenhosa, apresentando praticamente todas as fitofisionomias que englobam formações florestais, savânicas e campestres (IBGE, 1991, 1993). Quanto à geologia e à geomorfologia, a região da Serra da Canastra está na faixa de transição entre o domínio dos chapadões, recoberto por cerrados e penetrado por florestas-galerias ao norte, e o domínio dos mares de morros florestados ao sul, compreendendo uma região de maciços planálticos de estrutura complexa e planaltos sedimentares compartimentados (Ab'Saber, 1971). Os domínios de relevo predominantes são colinas onduladas e planaltos, com declividades 
que variam de 3\% a 20\%, incluindo a planície fluvial e morros e morrotes fortemente escarpados. A planície fluvial, frequentemente na declividade menor que 3\% em terrenos planos e levemente inclinados em direção ao canal principal, compreende a planície de inundação e terraços do Rio Grande, ao sul, caracterizando terrenos alagadiços (Brasil, 1983).

$\bigcirc$ clima regional é caracterizado pela sazonalidade, com chuvas no verão e inverno seco. A temperatura média do mês mais frio é inferior a $18{ }^{\circ} \mathrm{C}$ e a do mês mais quente não ultrapassa $22^{\circ} \mathrm{C}$. A área apresenta pluviosidade anual entre 1.000 e $1.500 \mathrm{~mm}$. $\bigcirc$ trimestre de dezembro a fevereiro, além de mais chuvoso, é o de maior excedente hídrico e o de escoamento superficial mais ativo (Souza, 1993).

\section{Fundamentação teórico-metodológica}

Este trabalho tem como base teórico-metodológica os princípios da análise integrada do ambiente, apoiada na concepção teórica da matriz de dissecação do relevo proposta por Ross (1994) (Figura 2-a). Essa matriz integra as variáveis referentes ao grau de entalhamento do vale (no eixo Y) e dimensão interfluvial média (no eixo X), sendo que a dissecação do relevo é diretamente proporcional à primeira variável e inversamente proporcional à segunda. Para o cálculo automatizado das variáveis entalhamento do vale e dimensão interfluvial, usou-se a metodologia de Guimarães et al. (2017). Na Figura 2, apresentam-se perfis de vales que representam cada valor de dissecação da matriz proposta por Ross (1994) (Figura 2-a), bem como a proposta de reclassificação da matriz (Figura 2-b) e a proposta por Guimarães et al. (2017) (Figura 2-c), além da estratificação da legenda (Figura 2-d).

\section{Figura 2 - (a) Perfil dos vales que representam cada classe de dissecação da matriz de Ross (1994), (b) proposta de classificação de Ross (1994), (c) proposta de Guimarães et al. (2017), (d) legenda Ross (1994)}

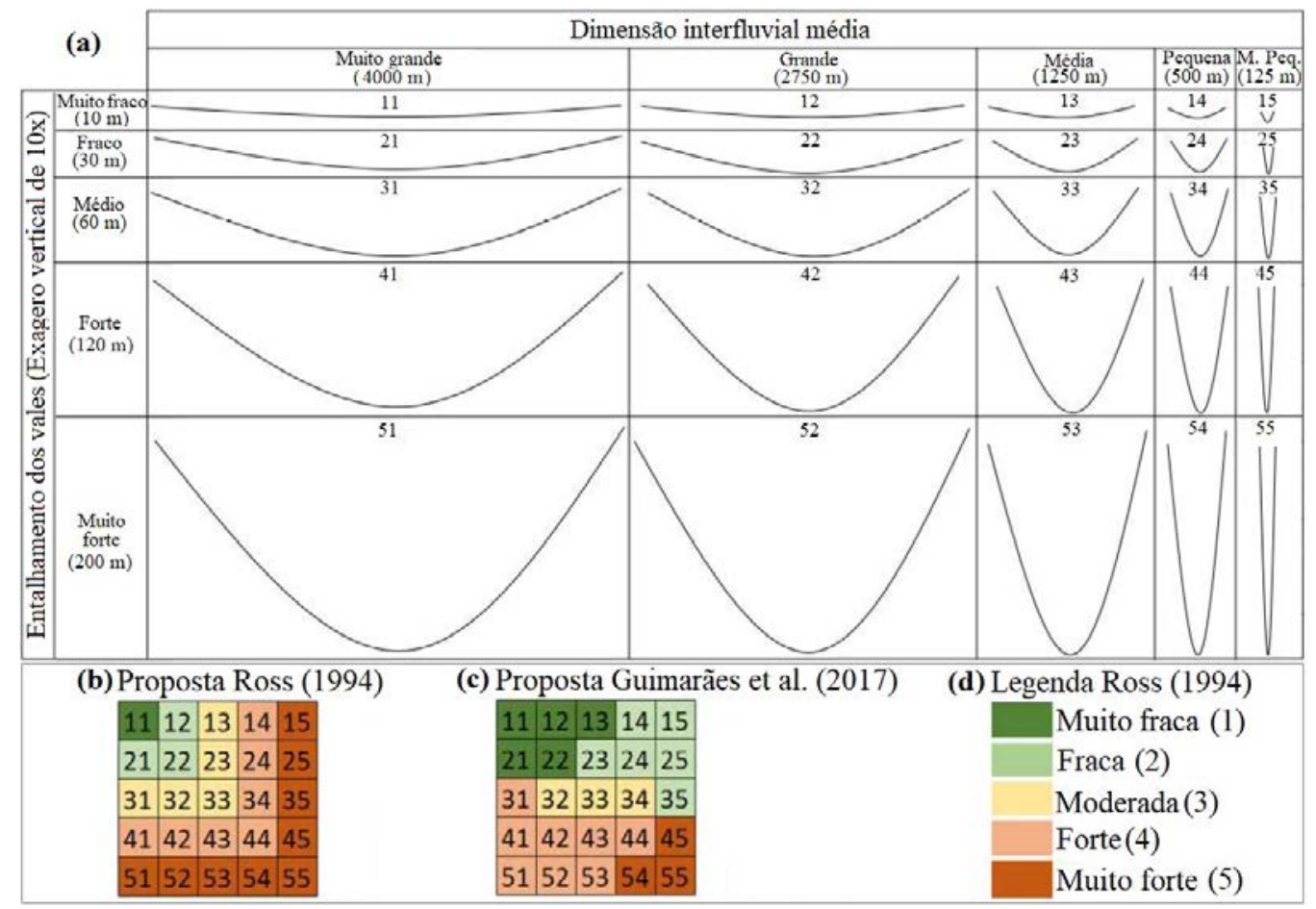

fonte: Adaptada de Guimarães et al. (2017). 
Baseando-se nessa matriz, neste trabalho é testada uma proposta fundamentada na técnica da geovisualização bivariada, por meio do qual se tem como resultado um mapa da dissecação do relevo. Este produto possibilita verificar cada variável, entalhamento do vale e dimensão interfluvial, separada e/ou de forma combinada. Segundo Stevens (2015), os mapas bivariados vão além de simplesmente mostrar duas variáveis; eles mostram onde as duas variáveis tendem a estar de acordo ou em desacordo. Se não houver expectativa de que as duas variáveis estejam relacionadas, uma variável bivariada coroplética não é a escolha certa (Stevens, 2015). Mostrar interrelação de duas variáveis também é o motivo pelo qual o número de classes em um mapa bivariado é maior do que a soma combinada de classes de cada variável sozinha. Se as variáveis individuais tiverem n classes, o mapa bivariado terá $n^{2}$ classes (Stevens, 2015). Tendo como base a matriz de Ross (1994) (Figura 2-a), foi realizado um experimento tendo, no eixo Y da legenda bivariada a representação do entalhamento do vale e, no eixo $X$ a representação da dimensão interfluvial. Há, portanto, a expectativa de que as duas variáveis estejam inter-relacionadas, resultando no índice de dissecação do relevo. Na Figura 3, ilustra-se como funciona a elaboração da legenda bivariada.

\section{Figura 3 - Legenda bivariada}
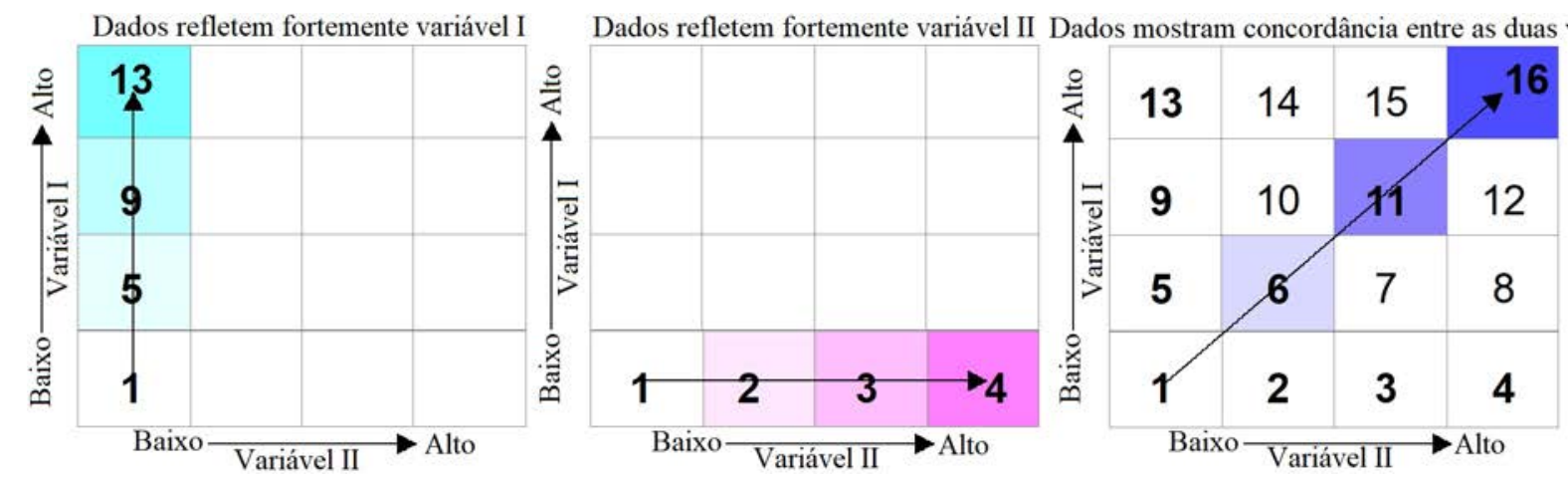

fonte: Adaptada de Stevens (2015).

No eixo Y, os dados refletem fortemente o grau de entalhamento dos vales (1, 5, 9 e 13), enquanto no eixo $X$, refletem a dimensão interfluvial média (1, 2, 3 e 4). Na diagonal, os dados exprimem a concordância entre as duas variáveis, resultando na dissecação do relevo (1, 6, 11 e 16). Os números na submatriz triangular inferior (7, 8 e 12) representam a dimensão interfluvial, enquanto os números da submatriz triangular superior $(10,14$ e 15) representam o entalhamento. $\bigcirc$ número 1 da legenda é neutro para as duas variáveis.

\section{Procedimentos técnicos}

Os procedimentos técnicos foram desenvolvidos de acordo com as etapas descritas no fluxograma da Figura 4.

A etapa inicial da pesquisa consistiu na criação de um banco de dados contendo imagens do sensor Palsar (phased array type l-band synthetic aperture radar) a bordo do satélite Alos (advanced land observing satellite) a partir de imagens SAR (synthetic aperture radar) adquiridas no modo FBS (fine beam), polarização $\mathrm{HH}$, órbita ascendente com resolução espacial de 12,5 m (Banda L), obtida do banco de dados do Alaska Satellite Facility (ASF). Consistiram nas cenas: AP_27102_FBS_F6780_RT1; AP_27102_FBS_F6770_RT1; AP_27102_FBS_F6760_RT1; AP_26854_FBS_F6780_RT1; AP_26854_FBS_F6770_RT1; AP_26854_FBS_F6760_RT1. 
Também foram utilizados dados secundários das bases cartográficas em formato shapefle referentes a estradas, massa d'água e outros elementos cartográficos, incluindo os municípios que abrangem a área de estudo, somados a dados secundários para validação dos resultados.

\section{Figura 4 - Fluxograma metodológico}

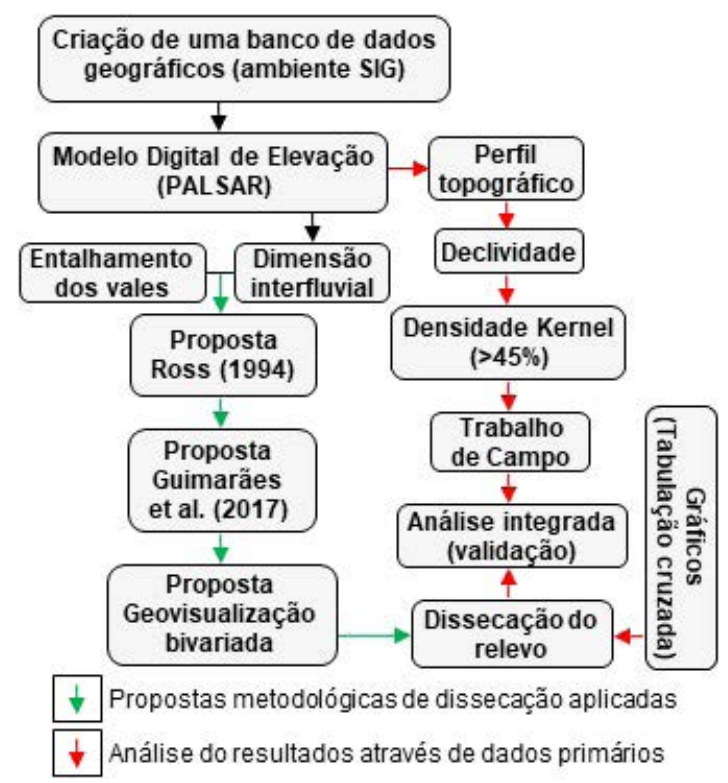

fonte: Elaborado pelos autores, 2020

conjunto de informações e dados foi organizado num banco de dados geográficos para tratamento, conversão, processamento e análise dos resultados e implementados em um sistema de informação geográfica por meio dos métodos de álgebra de campos por sobreposição ponderada. A escala de publicação dos mapeamentos é de 1:440.000.

\section{Tratamento das imagens Palsar}

Um mosaico foi construído, inicialmente, com as cenas do sensor Palsar. Depois foi estabelecida uma margem de segurança (buffer) para se ajustar ao limite da área de estudo, pois alguns dos algoritmos utilizados durante o processamento necessitam dos valores dos pixels adjacentes para serem processados; áreas situadas nas margens de segurança que estão mais perto das bordas da imagem estão mais sujeitas a erros e ruídos (Guimarães et al., 2017). Depois foi aplicado o algoritmo FillSinks para preencher as depressões espúrias, atribuindo novos valores aos pixels com anomalias, com base nas informações dos vizinhos mais próximos (Wang; Liu, 2006).

\section{Mapeamento das variáveis entalhamento dos vales e dimensão interfluvial média}

mapeamento de grau do entalhamento dos vales e da dimensão interfluvial média seguiu os procedimentos metodológicos descritos no trabalho de Guimarães et al. (2017). Para tanto, o autor destaca, especificamente, que no cálculo da dimensão interfluvial média, para delimitação das bacias de drenagem, é necessário determinar o limiar que define a área mínima de drenagem considerada bacia (Medeiros; Ferreira; Ferreira, 2009), sendo esse limiar dado pelo número de pixels. Ressalta-se que a escolha desse limiar é a única etapa que depende da decisão 
do pesquisador para execução da metodologia. A escolha do valor ideal depende do tamanho de pixel do MDE utilizado e das características do relevo da área de estudo (Guimarães et al., 2017). Ao contrário do trabalho de Guimarães et al. (2017), que utilizou imagens do MDE a partir de imagens do radar SRTM (shuttle radar topography mission), com resolução espacial de $30 \mathrm{~m}$, neste estudo foram utilizadas imagens Palsar, com resolução espacial de $12,5 \mathrm{~m}$. Assim, após os cálculos e testes, foi utilizado um limiar de 1724 (count/pixel) executado por meio da função conditional/con no software ArcGIS (Esri, 2016). Por fim, foram obtidas as variáveis, em formato raster: entalhamento dos vales e dimensão interfluvial média.

\section{Aplicação das propostas de dissecação do relevo de Ross (1994), Guimarães et al. (2017) e geovisualização bivariada}

Após a obtenção das duas variáveis, os rasters de grau de entalhamento dos vales e dimensão interfluvial foram reclassificados de acordo com a matriz proposta por Ross (1994) (Figura 2-a). Assim, de acordo com a matriz, o raster de entalhamento dos vales foi reclassificado da seguinte forma: 0 a 20 m (10); 20 a 40 m (20); 40 a 80 m (30); 80 a 160 m (40); maior que 160 m (50). Posteriormente, o raster da dimensão interfluvial média foi classificado da seguinte forma: 0 a 250 m (5); 250 a 750 m (4); 750 a 1.750 m (3). Não houve valores superiores a 1.750 m (2) e $3.750 \mathrm{~m}$ (1). Em seguida, as classes foram reclassificadas de modo a assumir os valores entre parênteses: eixo $Y$ entalhamento, eixo $\mathrm{X}$ dimensão interfluvial.

Para obter o índice de dissecação do relevo, foi feita a soma dos rasters obtidos pela função Plus utilizando a calculadora de raster do ArcGIS (Esri, 2016), segundo a qual cada pixel terá um valor de dissecação. Posteriormente, foram gerados dois mapas de dissecação: um pelo agrupamento das classes segundo a proposta de Ross (1994) (Figura 2-b), o outro pela proposta de Guimarães et al. (2017) (Figura 2-c).

$\mathrm{Na}$ aplicação da proposta de geovisualização bivariada para elaboração do mapa de dissecação do relevo, as variáveis referentes aos rasters de entalhamento dos vales e dimensão interfluvial média foram classificadas em quatro classes cada. No entanto, os limiares dos mapas reclassificados não foram os mesmos propostos na matriz de Ross (1994) (Figura 2-a); os intervalos foram definidos pelo algoritmo de quebras naturais (Jenks). Assim, os limiares propostos foram: para o eixo $\mathrm{Y}$ (entalhamento dos vales); 1-43 m (1); 44-112 m (5); 113-226 m (9); 227-628 m (13); e para o eixo X (dimensão interfluvial média); 1.080-1.919 m (4); 783-1.079 m (3); 530-782 m (2); 1-529 m (1). Em seguida, as classes foram reclassificadas de modo a assumir os valores entre parênteses: eixo $Y$ entalhamento, eixo X dimensão interfluvial, conforme a legenda bivariada (Stevens, 2015) (Figura 3). A combinação dos mapas por meio da técnica de geovisualização bivariada resultou no mapa da dissecação do relevo.

\section{Validação dos resultados}

Para validar os resultados, foram elaborados gráficos de tabulação cruzada a partir das classes estratificadas do mapa de densidade de Kernel. Esse foi feito com declividades superiores a 45\%. O mapa de Kernel foi reclassificado em cinco classes e estratificado em: muito baixa, 
baixa, moderada, forte e muito forte densidade. A partir dele, foram elaborados gráficos por meio da técnica de tabulação cruzada com as estratificações de Kernel e os resultados obtidos pelas metodologias e proposta deste trabalho.

Os mapas obtidos pelas estratificações propostas de Ross (1994) e Guimarães et al. (2017), foram reclassificados em três classes. Esse critério foi adotado porque o agrupamento do mapa com os valores de reclassificação proposto por Ross (1994), fornece três estratificações, assim foi usado o mesmo critério para o mapa de Guimarães et al. (2017), selecionando as três estratificações superiores. Seguindo o mesmo propósito e padrão, para elaboração do gráfico de tabulação cruzada, com as classes estratificadas do mapa de densidade de Kernel e o mapa dissecação bivariado, foram selecionadas as classes de dissecação $(6,11$ e 16), excluindo a número 1, por ser incomum para ambas as variáveis na legenda bivariada.

Também para análise dos resultados foi traçado um perfil topográfico em um ponto de observação registrado adjacente a BR-146, por meio de um trabalho de campo (07/01/2019), próximo ao município de São João Batista do Glória-MG. As coordenadas do ponto de observação consistem: $340.617 \mathrm{~m} \mathrm{E} \mathrm{/} \mathrm{7.728.97} \mathrm{1m} \mathrm{N,} \mathrm{numa} \mathrm{altitude} \mathrm{de} 748 \mathrm{~m}$ com aproximadamente $3.200 \mathrm{~km}$ de comprimento.

\section{Resultados e discussão}

\section{Aplicação das propostas de dissecação do relevo de Ross (1994) e Guimarães et al. (2017)}

A Figura 5 mostra a distribuição das classes das variáveis na área estudada e o Gráfico 1 apresenta a porcentagem de cada unidade dos mapas.

Ressalta-se que não foram obtidos na área de estudo valores correspondentes às combinações: 11, 12, 21, 22, 31, 32, 41, 42, 51, 52. Os valores mais baixos indicam áreas com menor dissecação do relevo, enquanto os mais altos, dissecação mais forte (Guimarães et al. 2017).

\section{Figura 5 - (a) Mapa de entalhamento dos vales, (b) Mapa da dimensão interfluvial média}

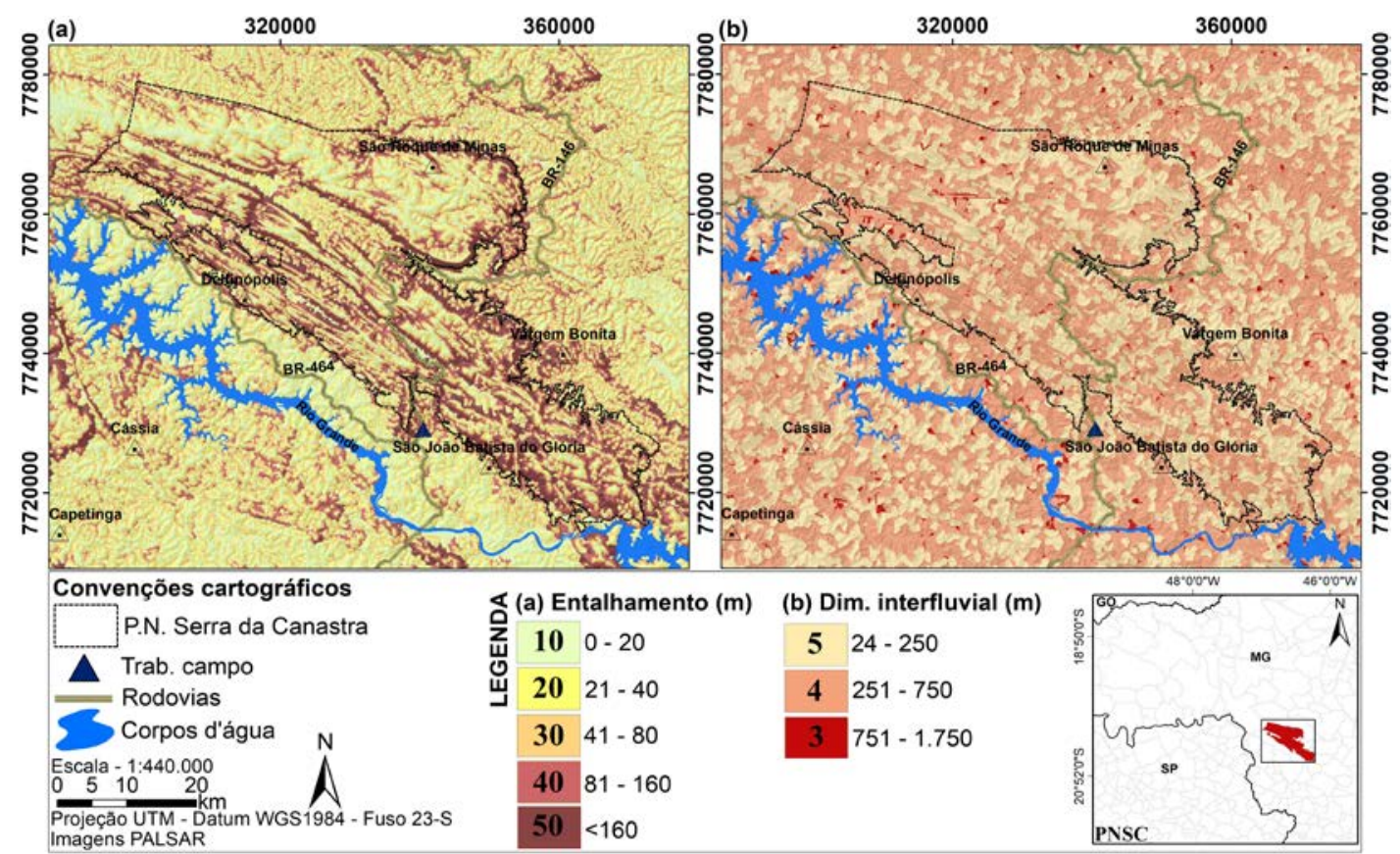

fonte: Elaborados pelos autores, 2020. 


\section{Gráfico 1 - Distribuição das variáveis: (a) entalhamento, (b) dimensão interfluvial (Ross, 1994)}
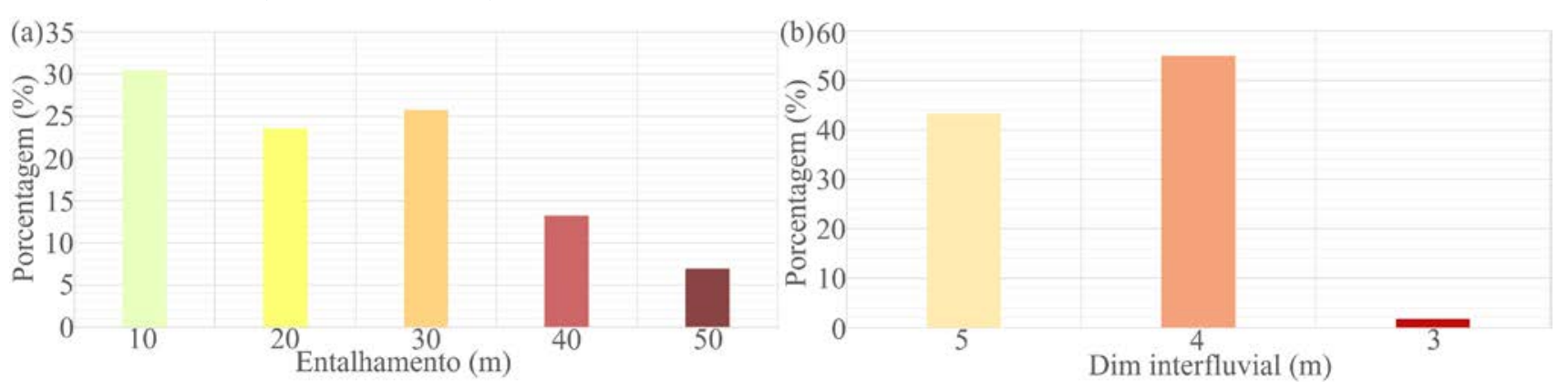

fonte: Elaborados pelos autores, 2020.

A Figura 6 mostra a distribuição das classes de dissecação na área estudada, seguindo a proposta da matriz de Ross (1994) (Figura 2-a) e o Gráfico 2 apresenta a porcentagem de cada unidade de dissecação do mapa.

Os mapas apresentaram legendas diferentes em função dessas propostas, por não apresentar os mesmos limiares de classificação. Na proposta de Ross (1994) (Figura 2-b), apenas a combinação 11 corresponde à classe de dissecação "muito fraca" (não houve essa classe na área de estudo); por outro lado, na proposta de Guimarães et al. (2017) (Figura 2-c), a classe "muito fraco" considera os intervalos de 11, 12, 13, 21 e 22. Consequentemente, os mapas apresentam estratificações diferentes em suas legendas (Ross, 1994) (Figura 2-d). Na proposta de Ross (1994) (Figura 2-a), não houve as classes "muito fraca" e "fraca" e, assim, o mapa apresentou apenas as classes "moderada", "forte" e "muito forte" de dissecação, ao contrário da proposta de Guimarães et al. (2017) (Figura 2-c), que apresentou todas as classes da legenda estratificada (Figura 2-d).

Figura 6 - Mapa com o agrupamento da matriz de Ross (1994) (Figura 2-a)

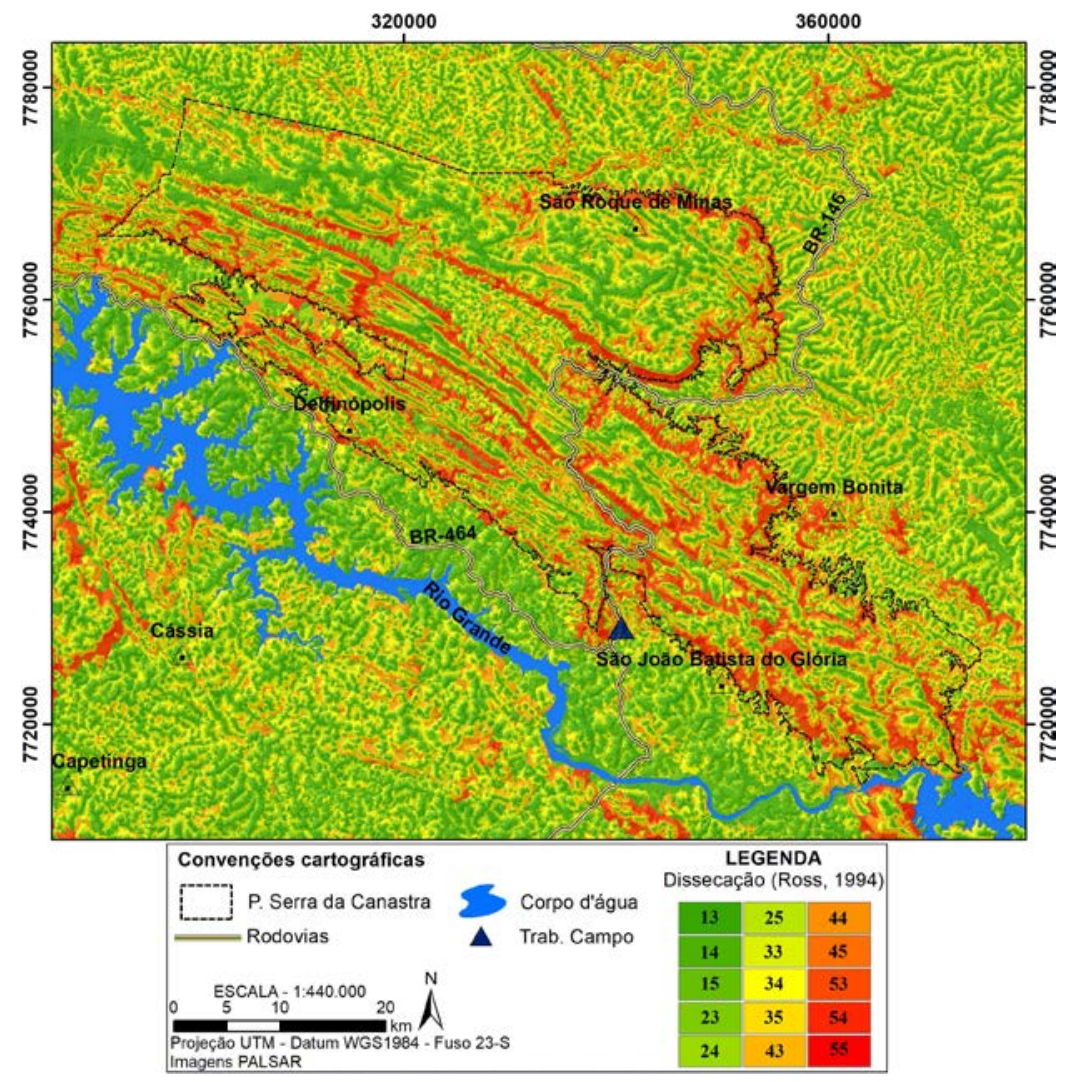

fonte: Elaborado pelos autores, 2020. 


\section{Gráfico 2 - Distribuição das classes do mapa de dissecação do relevo}

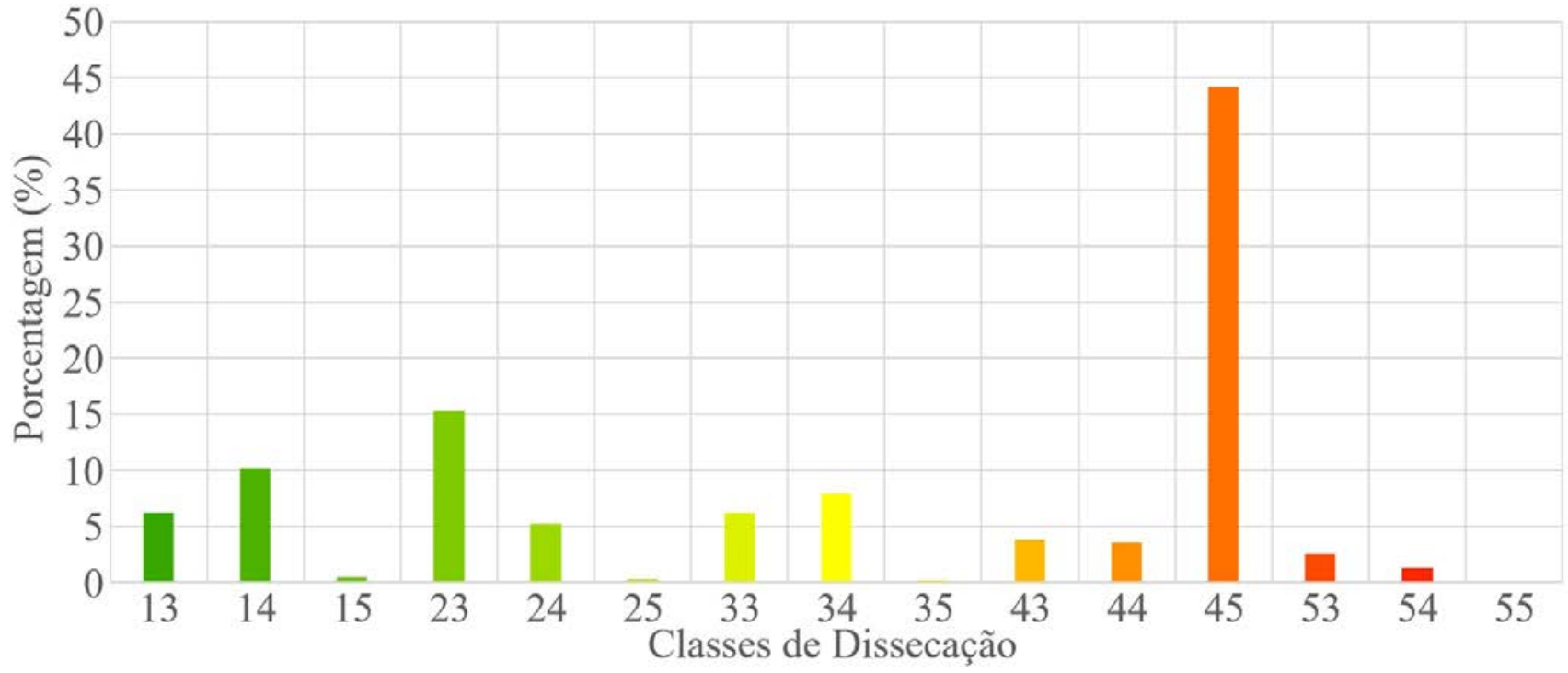

fonte: Elaborado pelos autores, 2020.

A Figura 7 mostra a distribuição das unidades de dissecação na área estudada obtidas pelas propostas de Ross (1994) (Figura 7-a) e Guimarães et al. (2017) (Figura 7-b) e o Gráfico 3 apresenta a porcentagem das classes dos mapas de dissecação.

Figura 7 - Mapas de dissecação do relevo: (a) Mapa estratificado conforme a proposta de Ross (1994) (Figura 2-b), (b) Mapa estratificado conforme a proposta de Guimarães et al. (2017) (Figura 2-c)

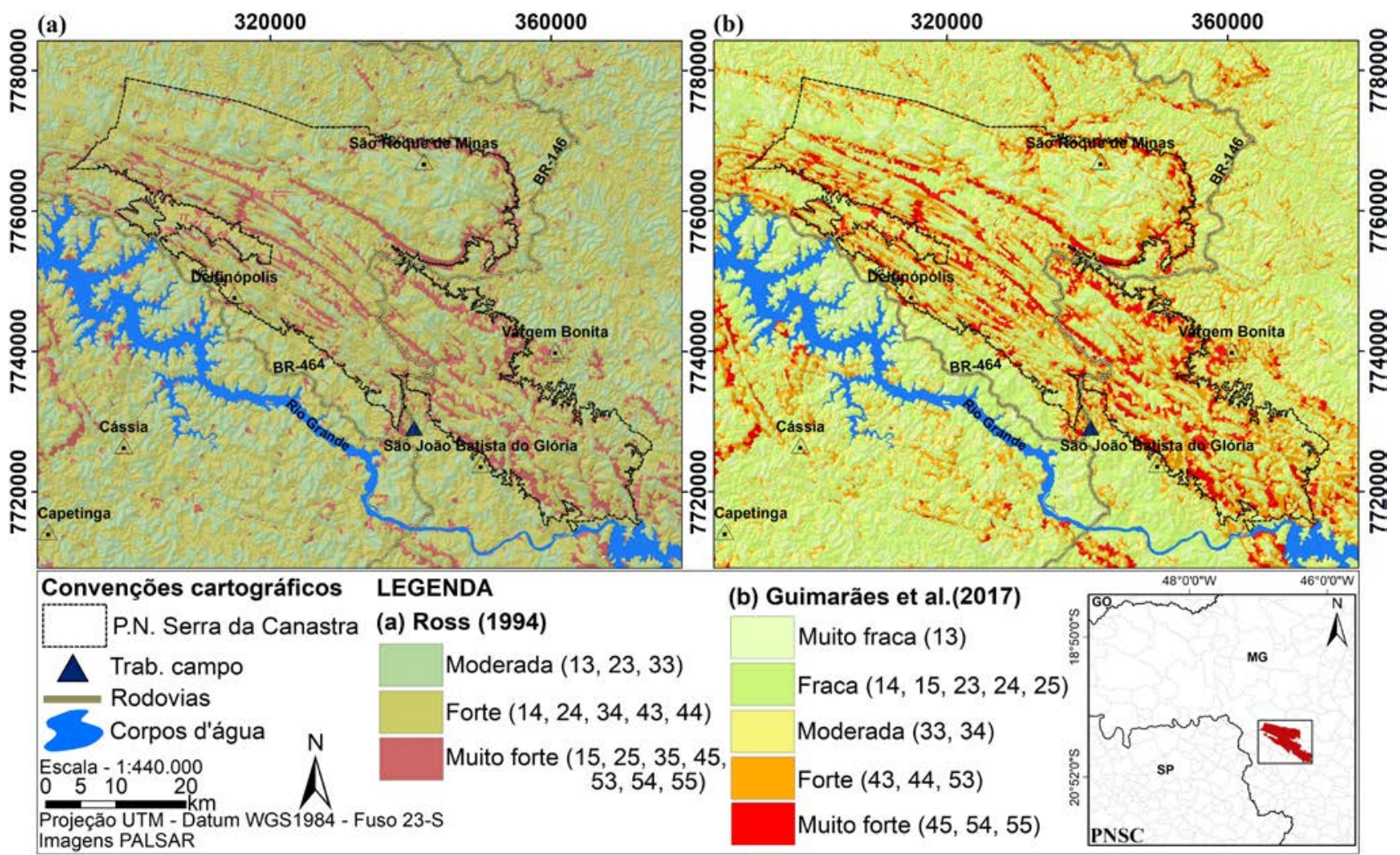

fonte: Elaborado pelos autores, 2020. 


\section{Gráfico 3 - Distribuição das classes dos mapas de dissecação do relevo}

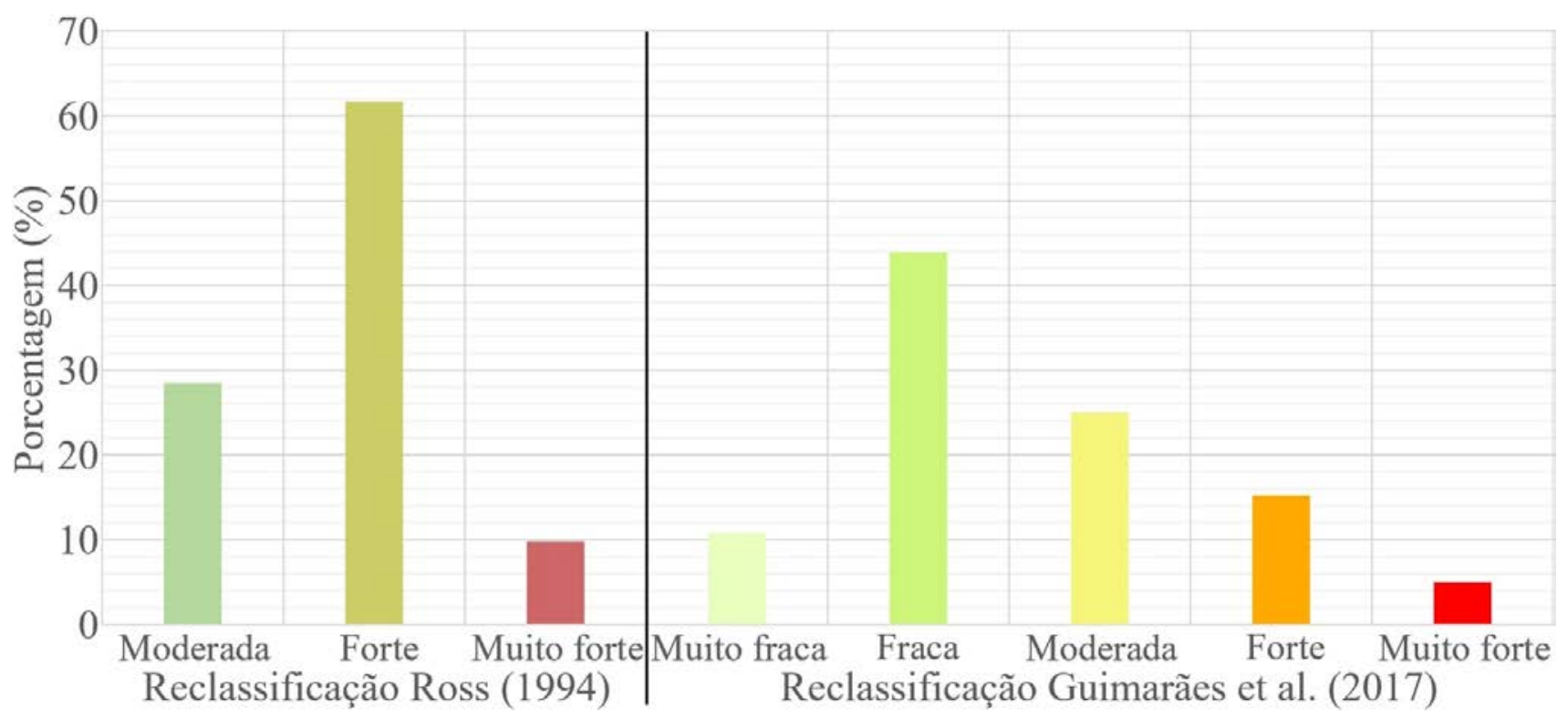

fonte: Elaborado pelos autores, 2020.

A classe "Forte" do mapa de Ross (1994) (Figura 7-a) foi a que apresentou maior porcentagem de dissecação, com aproximadamente $62 \%$ da área total, situada entre 9 e $45 \%$ de declividade. Ocupa áreas onduladas e fortemente onduladas, distribuídas em diferentes altitudes por toda área de estudo. A segunda classe, a "Moderada", ocupa 28\% da área total dissecada, situada entre 0 e $8 \%$ de declividade. Ocupa áreas planas e suavemente onduladas, também distribuídas por toda área de estudo em diferentes altitudes. Por fim, a classe de menor representação espacial na área estudada refere-se à classe "Muito forte", com aproximadamente 10\% da área. Situa-se nas declividades superiores acima dos $45 \%$, em áreas principalmente íngremes e escarpadas do PNSC, além de aparecerem em pontos dispersos, também em diferentes altitudes.

Com relação ao mapa conforme a proposta de Guimarães et al. (2017) (Figura 7-b), a classe "Fraca" foi a que apresentou maior abrangência espacial na área de estudo, com aproximadamente $44 \%$ de ocupação, situada entre 4 e $8 \%$ de declividade. É formada por áreas de relevo suavemente ondulado, distribuídas em baixas altitudes ao longo da área de estudo. Em seguida, encontra-se classe "Moderada", ocupando aproximadamente 25\% da área total. Situa-se entre 8 e 20\% de declividade, sob relevos ondulados, distribuídos em níveis altimétricos um pouco mais altos que a classe anterior. A classe "Forte" ocupa aproximadamente 15\% da área total, formada por relevo fortemente ondulado, entre 20 e $45 \%$ de declividade. Distribui-se em níveis altimétricos mais elevados que a classe anterior. Em seguida, a classe "Muito fraca", ocupando aproximadamente $11 \%$ da área total, formada em relevos planos. Distribui-se por toda a área de estudo em níveis altimétricos baixos, formados principalmente por fundo de vales e planícies de inundação. Por fim, a classe "Muito forte", ocupando aproximadamente $5 \%$ da área total, formada por declividades elevadas, acima dos $45 \%$. Ocupa áreas íngremes escarpadas principalmente situadas no parque e nas bordas do mesmo, além, de aparecer em pontos dispersos em altitude mais elevada da área de estudos.

Conforme o Gráfico 3, as duas propostas apresentam resultados semelhantes para a classe "Muito forte", embora seja diferentes. Visualmente, apresentam um comportamento espacial equivalente de distribuição da dissecação do relevo, mapeado em áreas íngremes e 
escarpadas. Essas áreas estão situadas nas bordas que compreendem o limite do parque, nos principais divisores d'água.

Assim, do ponto de vista conceitual de Ross (1994) verifica-se que essa região do estado de Minas Gerais é mais suscetivel a processos erosivos, mas que, diante da realidade, isso não é uma afirmação totalmente válida, pois seriam necessárias mais informações e parâmetros para análise, em escala mais detalhada. Já na proposta de Guimarães et al. (2017) a representação cartográfica ressalta mais precismente as caracterísicas do terreno; comparadas com a declividade (Figura 1-b), as feições são suavemente expostas, nessa escala de análise.

\section{Geovisualização bivariada para mapear a dissecação do relevo}

A Figura 8 mostra a distribuição das variáveis reclassificadas de acordo com a proposta de geovisualização bivariada, entalhamento dos vales (Figura 8-a) e dimensão interfluvial (Figura 8-b) e o Gráfico 4 apresenta a porcentagem das classes nos dois mapas obtidos.

Os valores 1, 5, 9 e 13 são crescentes para o entalhamento, enquanto para a dimensão interfluvial os valores 4, 3, 2 e 1 são decrescentes.

Figura 8 - Variáveis com a proposta de geovizualização bivariada: (a) mapa de entalhamento, (b) mapa de dimensão interfluvial média

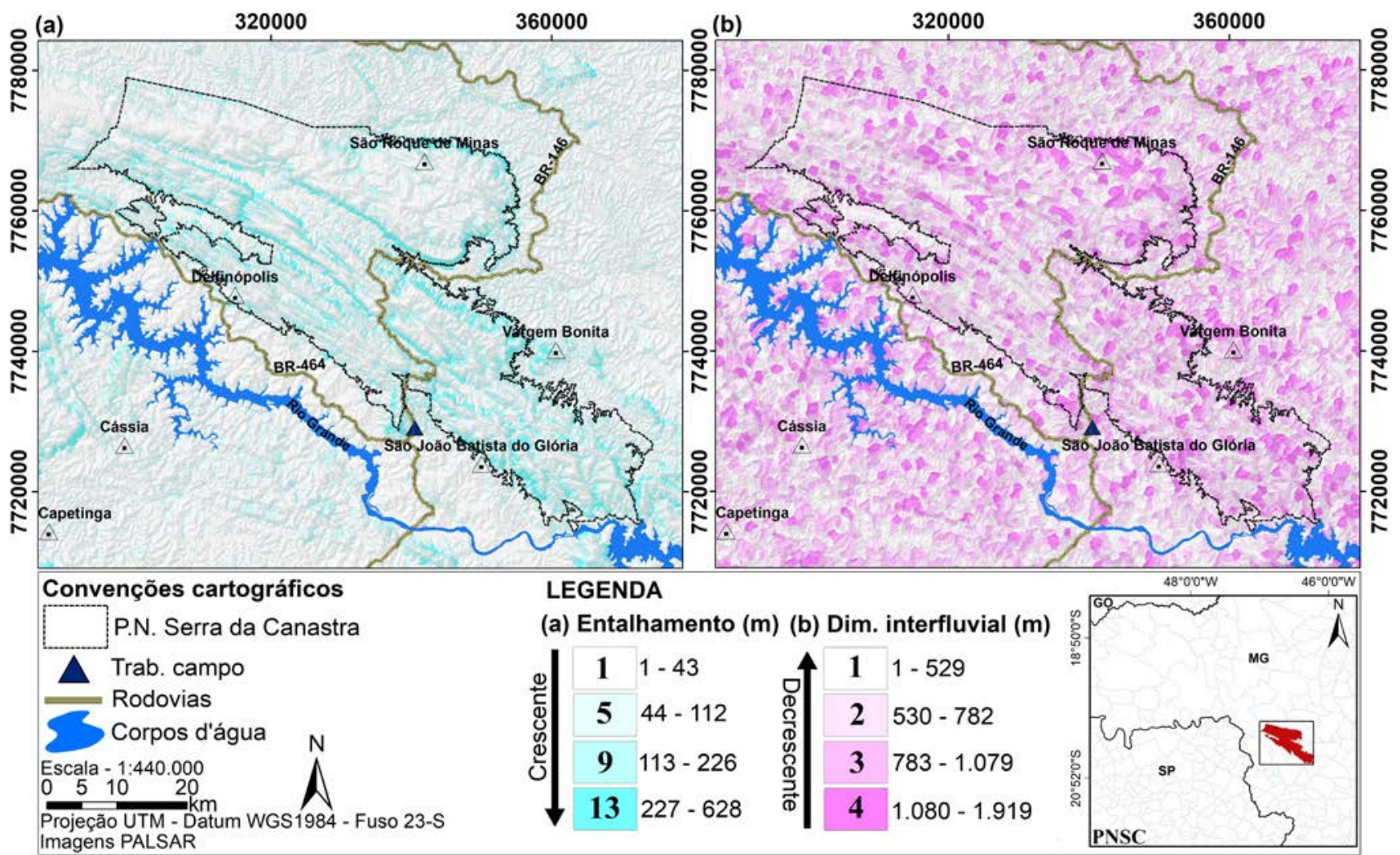

fonte: Elaborados pelos autores, 2020. 


\section{Gráfico 4 - Distribuição das variáveis bivariadas: (a) entalhamento, (b) dimensão interfluvial}
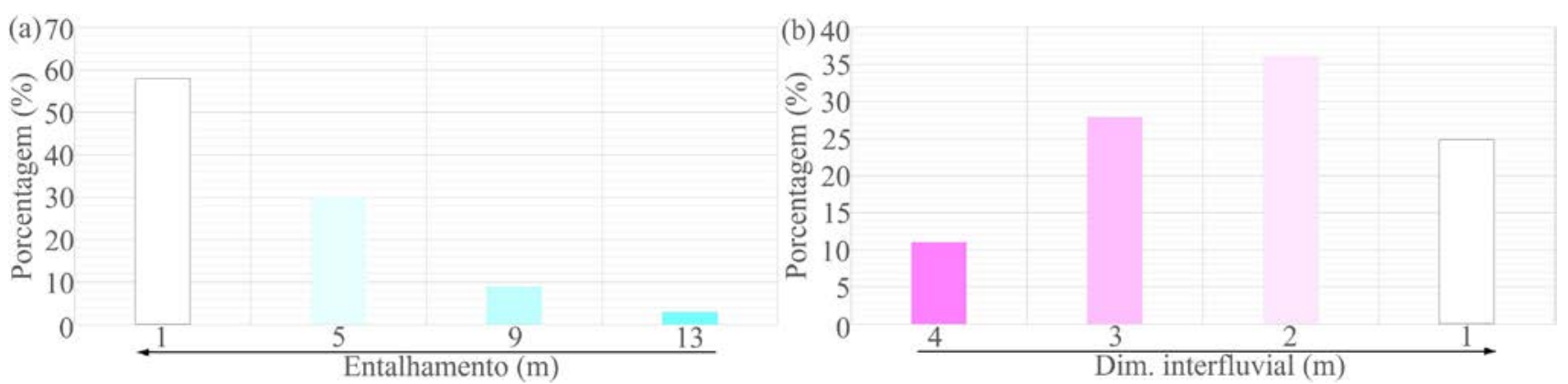

fonte: Elaborados pelos autores, 2020.

A Figura 9 mostra a distribuição das unidades de dissecação na área estudada, obtidas pela proposta da geovizualização bivariada, e o Gráfico 5 apresenta a porcentagem de cada unidade de dissecação na área de abrangência.

De maneira geral, os resultados também mostram que a dissecação é maior em áreas onde predominam vales encaixados e profundos, escarpados, em forma de $\mathrm{V}$, com dimensão interfluvial pequena (eixo X). Essas áreas caracterizam-se por apresentarem alto entalhamento (eixo Y), estando associadas aos locais de altas declividades. Por outro lado, a dissecação é menor em áreas planas, com maior dimensão interfluvial.

A legenda bivariada apresenta uma distribuição espacial das áreas dissecadas similar à das propostas apresentadas anteriomente, principalmente nas áreas de dissecação "muito forte", que na legenda do mapa referem-se ao número 16.

\section{Figura 9 - Mapa bivariado da dissecação do relevo}

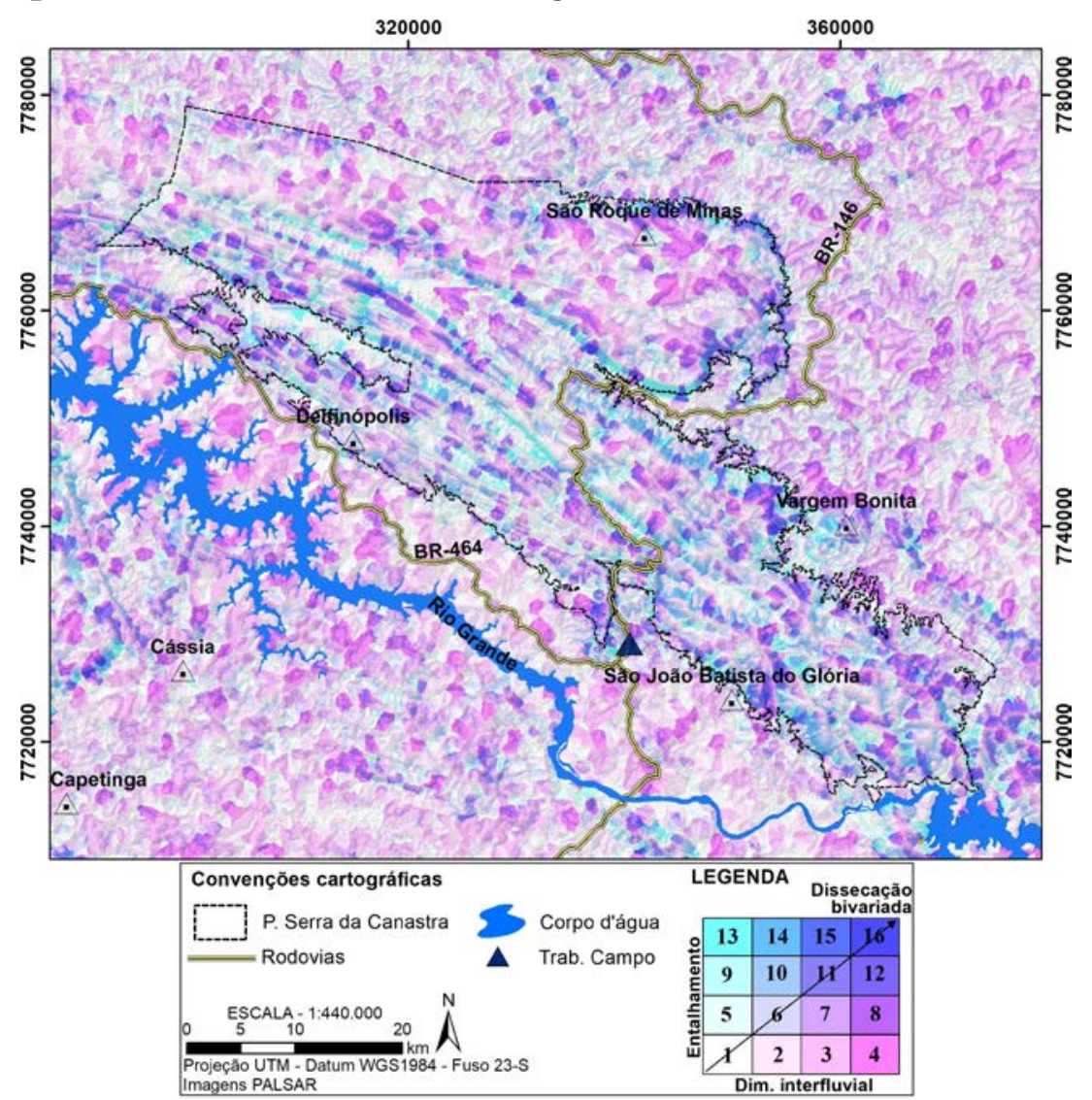

fonte: Elaborado pelos autores, 2020. 
Conforme o Gráfico 5, embora as classes apresentem representatividades espaciais diferentes aos resultados obtidos por meio das outras duas propostas, verifica-se um comportamento espacial equivalente de distribuição da dissecação do relevo, mapeado em áreas íngremes e escarpadas. Essas áreas estão situadas nas bordas que compreendem o limite do parque, nos principais divisores d'água. Em algumas regiões na borda (escarpas) do PNSC, algumas áreas que aparecem nos outros mapas (Figuras 7-a; 7-b) como dissecadas, na proposta bivariada são classificadas como entalhamento forte.

\section{Gráfico 5 - Distribuição das classes do mapa de dissecação bivariado: entalhamento (E), dimensão interfluvial (I) e dissecação (D)}

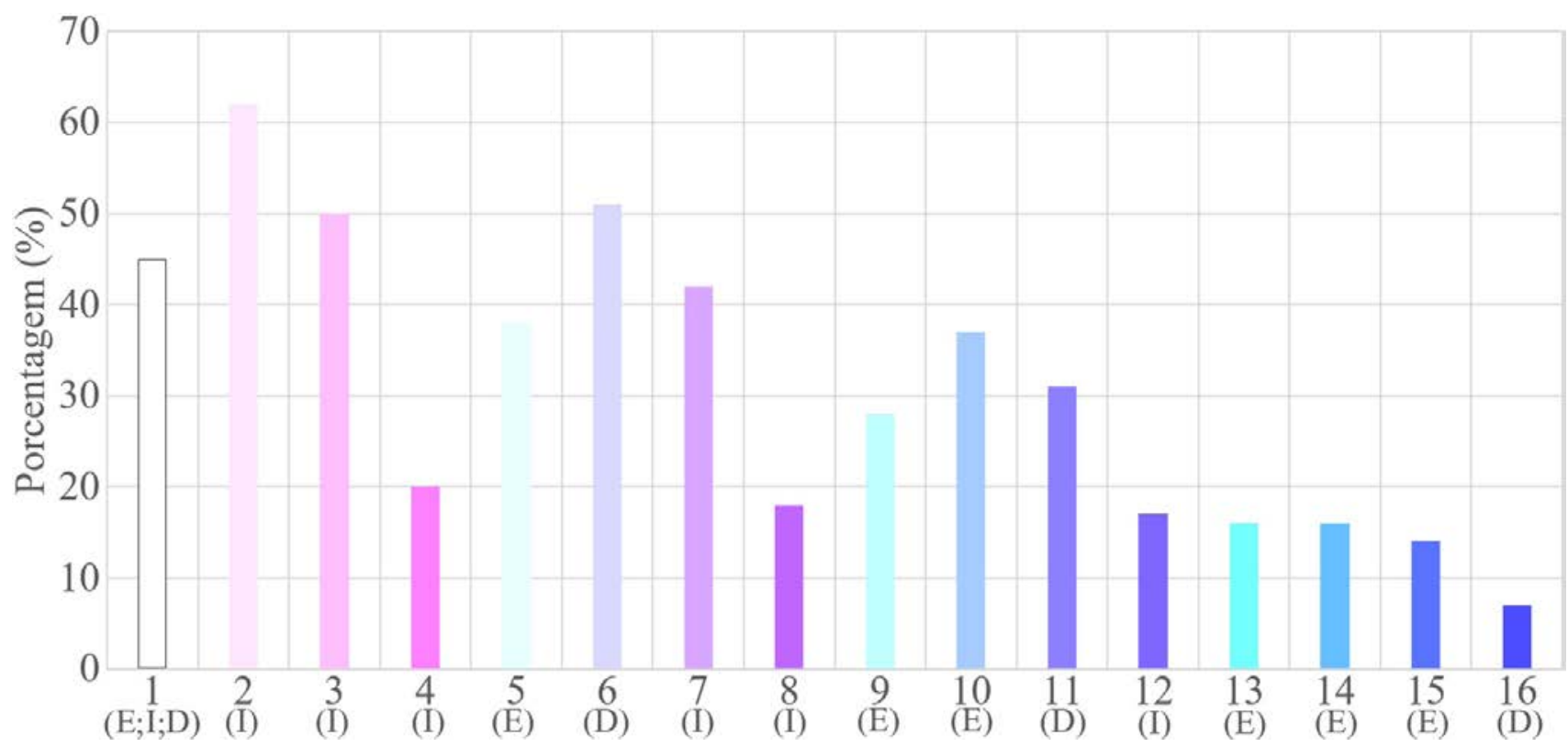

fonte: Elaborado pelos autores, 2020.

Conforme o Gráfico 5, a variável da dimensão interfluvial ocupa a maior área do mapa de dissecação (2, 3, 4, 7, 8 e 12); seguida pelo entalhamento (5, 9, 10, 13, 14 e 15), finalmente, a dissecação do relevo (6, 11 e 16).

$\mathrm{Na}$ Figura 10, apresenta-se a distribuição das unidades do mapa de densidade de Kernel e, no Gráfico 6, a porcentagem de cada mapa de dissecação considerando as classes do mapa de Kernel. No mapa de densidade de Kernel, considerando os pixels de declividade superiores a $45 \%$ (Figura 10) é possivel verificar áreas fortemente escarpadas e íngremes, distribuídas principalmente ao longo das bordas que contornam o parque e em algums locais isolados, em amplos divisores d'água.

Este aspecto comprova que os locais mais íngremes e escarpados estão situados ao longo das bordas do Parque. Se compararmos os mapas da dissecação, visual e espacialmente, eles apresentam uma distribuição equivalente e padronizada de dissecação, sobretuto nas áreas onde o índice de dissecação é mais forte. 
Figura 10 - Mapa de densidade de Kernel

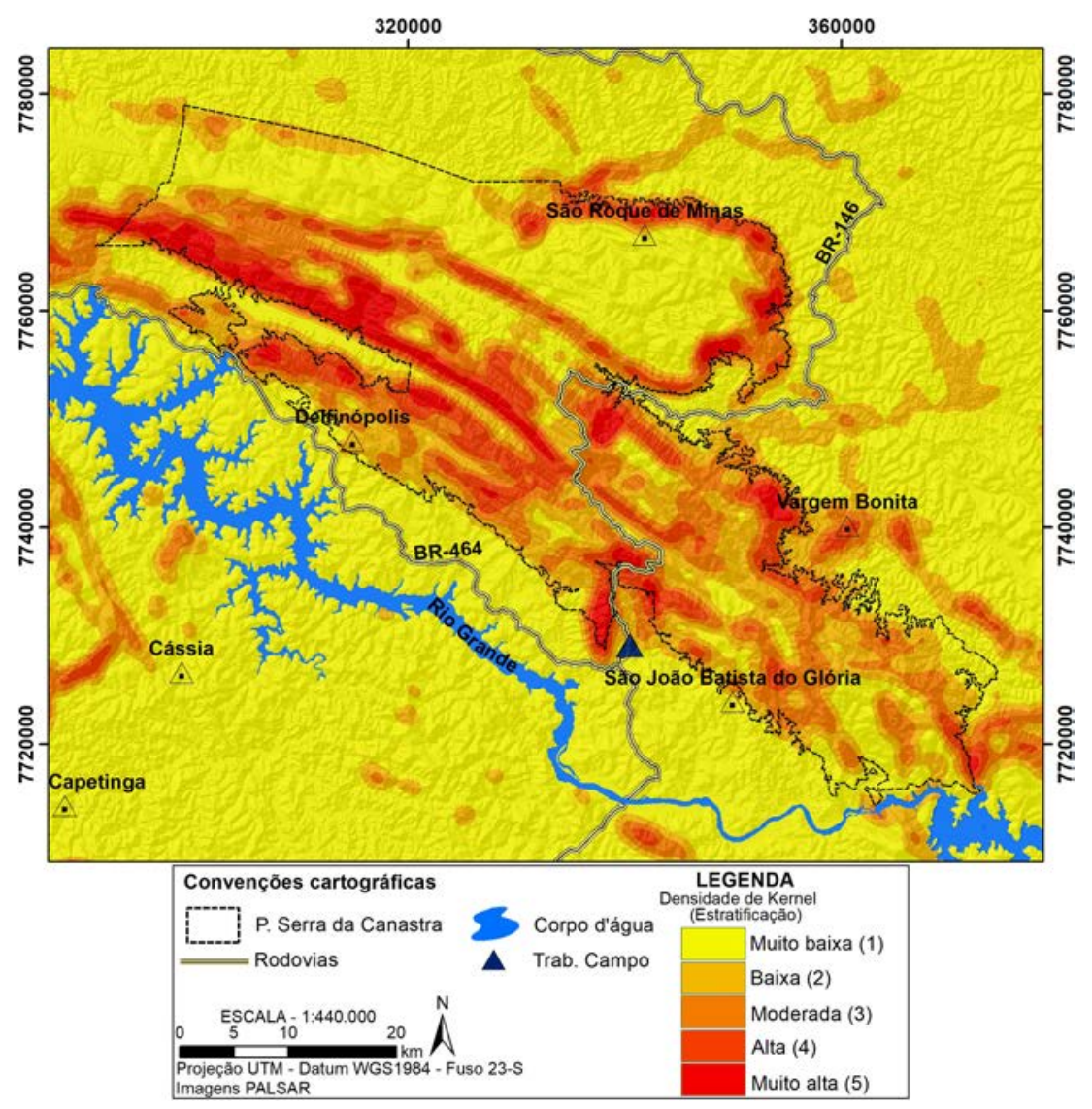

fonte: Elaborado pelos autores, 2020.

A análise do Gráfico 6 permite concluir que as três propostas do indíce de dissecação, Ross (1994), Guimarães et al. (2017) e bivariada, apresentam resultados equivalentes para a classe "Muito forte".

Gráfico 6 - Distribuição das dissecações bivariada, Ross (1994) e Guimarães et al. (2017) sobre as superfícies de Kernel (muito baixa, baixa, moderada, alta, muito alta)

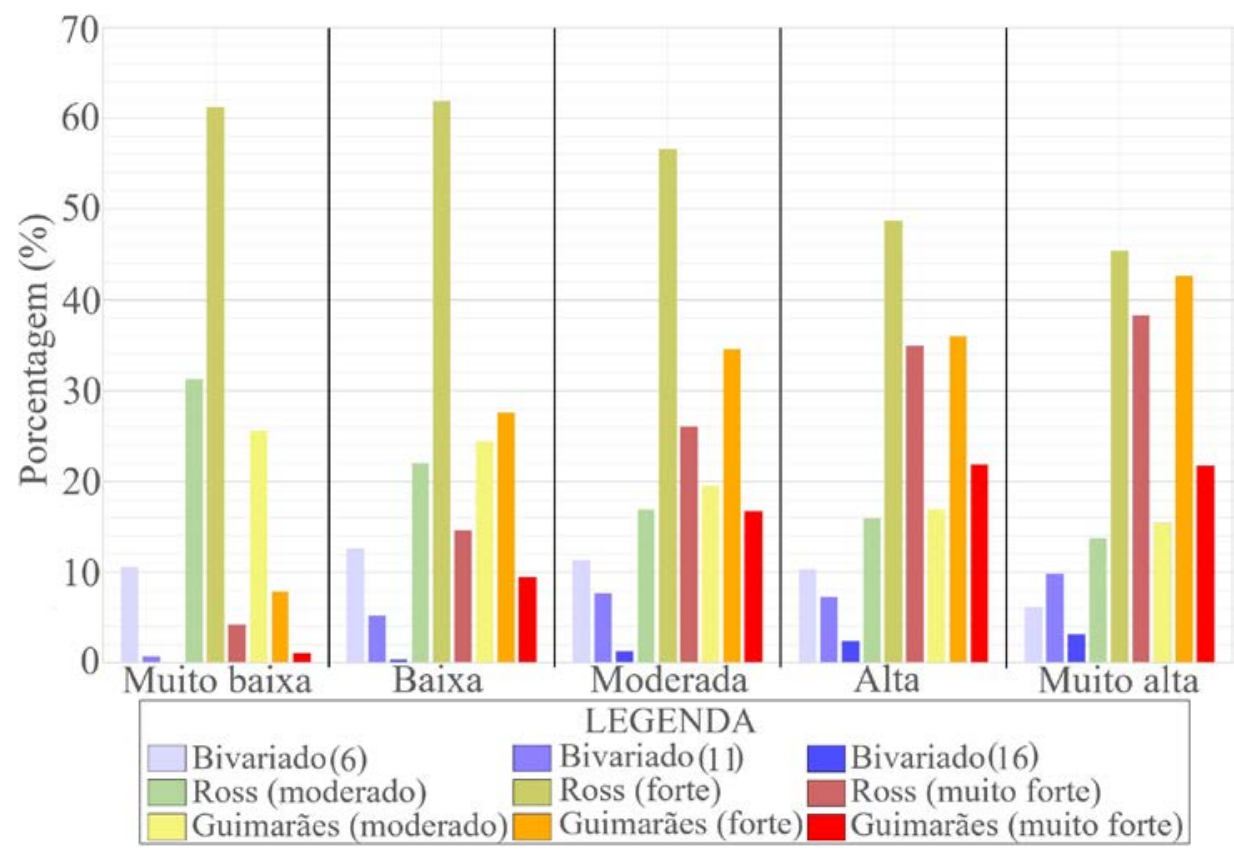


Na figura 11 é apresentado o perfil topográfico (A-B) na área onde foi realizado o trabalho de campo e obtidas as fotografias (Figuras 11-a a 11-c). Foram identificados quatro compartimentos: no compartimento 1, situado em torno de $700 \mathrm{~m}$ de altitude, pode-se verificar nas fotografias correspondentes $(\mathrm{a}, \mathrm{b})$ que o relevo é constituído por vales mais amplos e declividades menos acentuadas. No mapa obtido por geovisualização bivariada, a dimensão interfluvial é o fator mais influente. Na proposta de Ross (1994), esse compartimento aparece como área de dissecação moderada e na proposta de Guimarães et al. (2017) apresenta-se como área de transição, de dissecação muito fraca a moderada. No compartimento 2, situado a cerca de $750 \mathrm{~m}$ de altitude (fotografia b), os vales se tornam mais entalhados, com presença de áreas mais íngremes, conforme indicado no mapa obtido pela geovisualização bivariada. Nas outras propostas, aumenta a representatividade das classes de dissecaçao moderada e forte. No compartimento 3, situado em torno de $800 \mathrm{~m}$ de altitude, observa-se que o relevo é um pouco mais dissecado (fotografias a e c) e com maior influência do entalhamento, com a presença de escarpas no sopé da Serra da Canastra. Isso é indicado nas três propostas pela prevalência das classes de relevo fortemente a muito fortemente dissecado.

Por fim, no compartimento 4, no topo da serra, o relevo apresenta-se fortemente dissecado para todas as propostas (fotografia c).

\section{Figura 11 - Perfil topográfico (A-B) em que são apresentadas fotografias obtidas em campo e o produto das três propostas de mapeamento da dissecação}

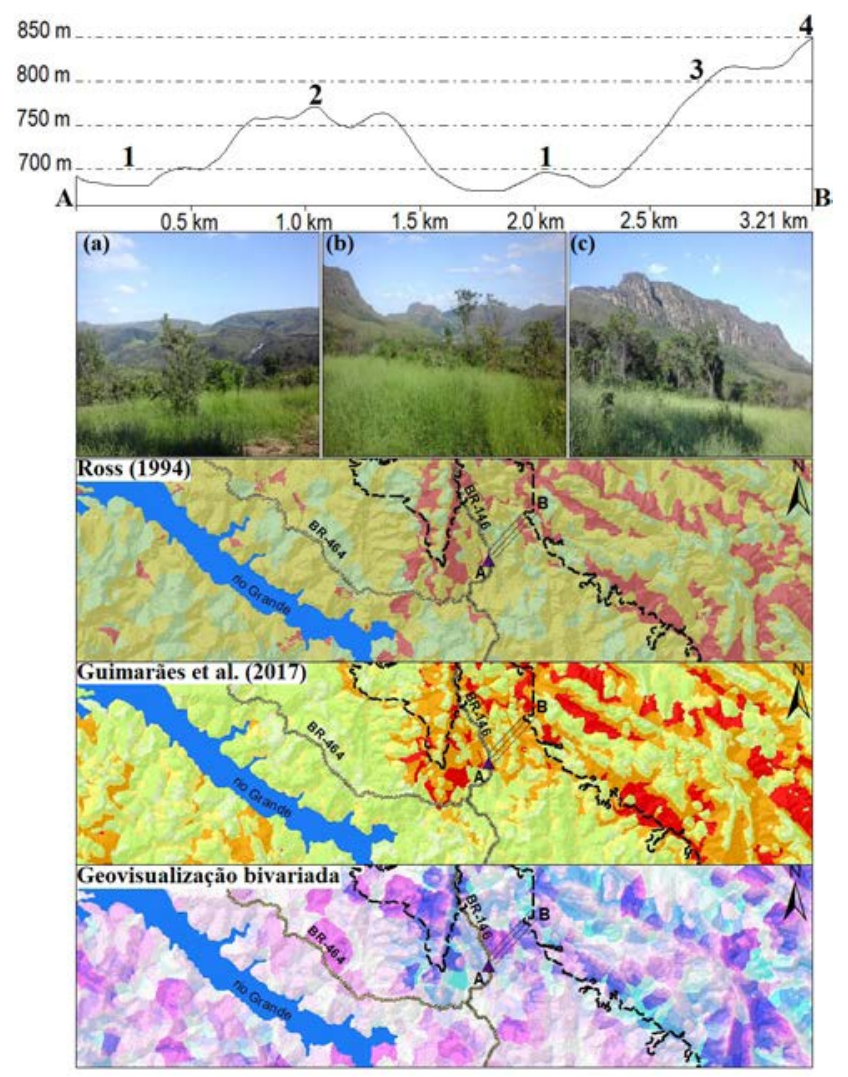

fonte: Elaborado pelos autores, 2020. 


\section{Considerações finais}

Neste trabalho, foi proposta uma metodologia de fácil execução e visualização para mapear a dissecação do relevo sem a necessidade da interferência do tomador de decisões. A vantagem da metodologia proposta é sua aplicabilidade em qualquer região geográfica, independentemente da base de dados utilizada, pois a classificação das variáveis não segue os mesmos limiares dos valores propostos na matriz da dissecação de Ross (1994) (Figura 2-a), podendo mapear áreas com qualquer intervalo altimétrico. A partir da legenda bivariada, considerando os resultados obtidos, foi possível mapear e distinguir as variáveis entalhamento dos vales e dimensão interfluvial distribuídas em toda a área de estudo.

A proposta da legenda bivariada para mapear a dissecação do relevo mostrou-se eficiente, na medida em que precisão e fidelidade foram satisfatórias em relação aos aspectos reais do terreno. Os produtos obtidos, somados aos perfis, às fotos e aos gráficos, mostraram correlação espacial com os outros mapeamentos realizados por propostas existentes na literatura brasileira. As três propostas apresentaram maior correspondência, principalmente onde a dissecação é "muito forte", nas áreas íngremes e escarpadas do parque e em áreas adjacentes com declive acentuado.

Ressalte-se que a análise espacial dos mapeamentos foi feita numa escala que permitiu ver de modo dinâmico uma área geográfica, o que é importante sobretudo por ser um Parque Nacional onde há atividades turísticas e um entorno com diversas atividades econômicas. Embora não tenha sido o foco deste trabalho, esse tipo de análise pode subsidiar medidas de planejamento para melhoria da preservação e do controle no parque, principalmente em áreas suscetíveis a processos erosivos e escorregamentos e áreas de risco.

Os resultados obtidos na área e analisados por meio de perfil topográfico, fotografias e correlação com o mapa de Kernel em cada superfície mostram a confiabilidade da metodologia proposta. Para trabalhos futuros, sugere-se o uso de imagens de modelos digitais de terreno (MDT) ou modelos de elevação com melhor resolução espacial, principalmente para aplicação em escalas mais detalhadas, além de produtos cartográficos primários e secundários que ajudem análises e interpretações. Para complementar a análise dos resultados, sugere-se ainda que se considerem outras variáveis significativas para a dissecação do relevo como as litológicas, estruturais e climáticas.

\section{Referências}

AB'SABER, A. N. A organização natural das paisagens inter e subtropicais brasileiras. In: SIMPÓSIO SOBRE O CERRADO, 3., 15-19 jun. 1971, São Paulo. Anais... São Paulo, 1971. p. 1-14.

AlBUQUERQUE, E. M.; ANDRADE, S. C. P.; MORAES, H. F; DINIZ, J. M. T; SANTOS, C. Análise do comportamento do NDVI e NDWI sob diferentes intensidades pluviométricas no município de Sousa-PB. Revista Estudos Geoambientais, Rio Tinto, PB, v. 1, n. 1, 2014.

BRASIL. Ministério das Minas e Energia. Secretaria Geral. Projeto Radambrasil. Folha SF.23/24 Rio de Janeiro/Vitória: geologia, geomorfologia, solos, vegetação e uso potencial da terra, Rio de Janeiro. 1983.

ESRI Inc. ArcMap - versão 10.5.1. Redlands, CA, 2016.

GUIMARÃES, F. S.; CORDEIRO, C. M.; BUENO, G. T.; CARVALHO, V. L. M.; NERO, M. A. Uma proposta para automatização do Índice de dissecação do relevo. Revista Brasileira de Geomorfologia, São Paulo, v. 18, n. 1, p. 155-167, 2017. 
IBGE. INSTITUTO BRASILEIRO DE GEOGRAFIA E ESTATÍSTICA. Mapa de vegetação do Brasil. Rio de Janeiro: IBGE, 1993.

IBGE. INSTITUTO BRASILEIRO DE GEOGRAFIA E ESTATÍSTICA. Classificação da vegetação brasileira adaptada a um sistema universal. Rio de Janeiro: IBGE, 1991.

MEDEIROS, L. C.; FERREIRA, N. C.; FERREIRA, L. G. Avaliação de modelos digitais de elevação para delimitação automática de bacias hidrográficas. Revista Brasileira de Cartografia, n. 61, n. 2, p. 137-151, 2009. Disponível em: http://www.seer.ufu.br/index.php/ revistabrasileiracartografia/article/view/44844/23855. Acesso em: 15 fev. 2021.

QUEIROZ NETO, J. P. Sistemas de representação cartográfica empregados nas regiões do Parateí, São Pedro e Marilia. In: COLÓQUIO INTERDISCIPLINAR FRANCOBRASILEIRO ESTUDO E CARTOGRAFIA DE FORMAÇÕES SUPERFICIAIS E SUAS APLICAÇÕES EM REGIÕES TROPICAIS, 1982, São Paulo. Anais... São Paulo: DG-FFLCH, 1978. v. I. p. 19-32.

ROSS, J. L. S. Análise empírica da fragilidade dos ambientes naturais antropizados. Revista do Departamento de Geografia, v. 8, p. 63-74, 1994. doi: https://doi.org/10.7154/ RDG.1994.0008.0006.

SOUZA, S. M. T. Deflúvios superficiais no estado de Minas Gerais. Belo Horizonte: Hidrossistemas/Copasa, 1993.

STEVENS, J. Bivariate choropleth maps: a how-to guide. [S.I.], Feb. 2015. Disponível em: https://www.joshuastevens.net/cartography/make-a-bivariate-choropleth-map/. Acesso em: 12 fev. 2021.

WANG, L.; LIU, H. An efficient method for identifying and filling surface depressions in digital elevation models for hydrologic analysis and modelling. International Journal of Geographical Information Science, v. 20, n. 1, p. 193-213, 2006. doi: https://doi.org/ 10.1080/13658810500433453.

\section{Contribuição dos autores}

José Roberto Mantovani: levantamento e estruturação do banco de dados geográficos, aplicação das metodologias disponíveis na literatura, implementação da metodologia proposta no estudo, por meio de geoprocessamento e cartografia digital, confecção dos mapas e das figuras, análise dos dados e revisão textual.

Guilherme Taitson Bueno: avaliação e sistematização estrutural do texto e comparação da metodologia com outras disponíveis na literatura brasileira, avaliação dos resultados e revisão geral do texto e das figuras.

Recebido em: 17 jun. 2020

Aprovado em: 9 dez. 2020 